\title{
White-coat hypertension and incident end-stage renal disease in patients with non-dialysis chronic kidney disease: results from the C-STRIDE Study
}

\author{
Qin Wang ${ }^{1}$, Yu Wang ${ }^{1 *}\left(\mathbb{0}\right.$, Jinwei Wang ${ }^{1}$, Luxia Zhang ${ }^{1,2}$, Ming-hui Zhao ${ }^{1,3}$ and the Chinese Cohort Study of \\ Chronic Kidney Disease (C-STRIDE)
}

\begin{abstract}
Background: Controversy remains whether white coat hypertension (WCH) is associated with renal prognosis in patients with chronic kidney disease (CKD).

Methods: In the present multicenter, prospective study, we analyzed data of participants with CKD stage 1-4 from the Chinese Cohort Study of Chronic Kidney Disease (C-STRIDE). WCH was defined according to two criteria as follows: A, clinical blood pressure (BP) $\geq 140 / 90 \mathrm{~mm} \mathrm{Hg}$ and average 24-h ambulatory BP < 130/80 mm Hg; B, clinical $B P \geq 130 / 80 \mathrm{~mm} \mathrm{Hg}$ and daytime ambulatory $\mathrm{BP}<130 / 80 \mathrm{~mm} \mathrm{Hg}$. Renal outcome was defined as initiation of renal replacement therapy. The association of WCH with renal events was evaluated by Cox regression model.

Results: A total of 1714 patients with CKD were included in the present analysis. The mean age of the population was $48.9 \pm 13.8$ years and $56.8 \%$ were men. The mean baseline estimated glomerular filtration rate (eGFR) was $52.2 \pm 30.1 \mathrm{ml} / \mathrm{min} / 1.73 \mathrm{~m}^{2}$ and urinary protein was $1.0(0.4,2.4) \mathrm{g} /$ day. The overall prevalence of WCH was $4.7 \%$ and $16.6 \%$ according to criteria $A$ and $B$, respectively. Incidence rates of renal events were 49.58 and 26.51 according to criteria A and B, respectively, per 1000 person-years during a median follow-up of 4.8 years. After full adjustment, WCH was associated with an increased risk of renal event (criterion A: hazard ratio 2.36, 95\% confidence interval 1.29-4.34; for criterion B: hazard ratio 1.90, 95\% confidence interval 1.04-3.49) compared with patients with normal BP.
\end{abstract}

Conclusions: $\mathrm{WCH}$ is associated with a greater risk for renal events in non-dialysis dependent Chinese patients with CKD.

Keywords: Ambulatory blood pressure monitoring, White coat hypertension, Chronic kidney disease, End-stage renal disease

\footnotetext{
*Correspondence: ddwangyu@sina.com

${ }^{1}$ Renal Division, Department of Medicine, Peking University First Hospital, Institute of Nephrology, Peking University, Key Laboratory of Renal

Disease, National Health and Family Planning Commission of the People's Republic of China, Key Laboratory of Chronic Kidney Disease Prevention and Treatment, Ministry of Education, Beijing 100034, China

Full list of author information is available at the end of the article
}

\section{Background}

Chronic kidney disease (CKD) is a leading public health challenges with a high prevalence of hypertension. Elevated blood pressure (BP) is one of the major contributors to progressive loss of renal function and development of cardiovascular disease (CVD) in patients with CKD [1]. Accurate diagnosis and treatment of hypertension are important in managing patients with CKD. Traditionally, diagnosis and 
management of hypertension were based on clinical BP (CBP) measurement. Since the development of the ambulatory $\mathrm{BP}$ (ABP) monitoring method, which can evaluate BP throughout the 24-h cycle in nonmedical settings, an increasing amount of evidence has suggested that $\mathrm{ABP}$ is correlated better with long-term prognosis compared with CBP [2,3].

Four different BP patterns have been identified by a combination of arbitrary $\mathrm{CBP}$ and $\mathrm{ABP}$ cut-off values as normal BP (NT), white coat hypertension (WCH), masked hypertension ( $\mathrm{MH})$, and sustained hypertension $(\mathrm{SH})$. In contrast to the definite prognostic value of $\mathrm{MH}$ and $\mathrm{SH}$, the prognostic value of $\mathrm{WCH}$ is still controversial in primary hypertension and hypertensive patients with CKD. WCH is defined as the condition in which CBP, but not out-of-office BP, is elevated. In some studies, $\mathrm{WCH}$ was associated with a greater prevalence of target organ damage [4-6] and worse prognosis [7] compared with NT in patients with CKD. However, in other studies, no differences in the risk of end stage renal disease (ESRD) and CVD were reported between these two groups $[8,9]$.

This study aimed to assess whether $\mathrm{WCH}$ is associated with the risk of ESRD in individuals with CKD.

\section{Methods}

\section{Participants}

The Chinese Cohort Study of Chronic Kidney Disease (C-STRIDE) is a large, nationwide, multicenter, prospective cohort study of patients with CKD in which BP was evaluated on the basis of office and out-of-office measurements in a subgroup of patients at enrollment. The C-STRIDE included 39 hospitals located in 22 provinces of China. The design and method of C-STRIDE have been described in detail elsewhere [10-12]. The inclusion criteria, exclusion criteria and baseline characteristics of the cohort are listed in Additional file 1: Table S1. Enrollment started in November 2011 and 3700 patients were enrolled by December 2016. A total of 2114 patients had ABP and CBP measurements at enrollment. Among them, 400 patients were excluded from the present analysis because of invalid ABP and CBP measurements. Finally, the data of 1714 patients with CKD were collected and analyzed. Comparison of baseline characteristics of participants who were included and excluded in the current analysis is shown in Additional file 1: Table S2. The study was approved by the Ethics Committee of Peking University First Hospital and the entire protocol was in adherence with the Declaration of Helsinki. All participants signed written informed consent before data collection.

\section{Blood Pressure measurements}

CBP was measured with a mercury sphygmomanometer for three times after the participants had sat quietly for 5 to $10 \mathrm{~min}$. Measurements were performed by an experienced nurse, who was unaware of the results of ABP readings. The mean of three consecutive readings was recorded as CBP for analysis. Twenty-four-hour ABP monitoring was performed via calibrated devices in each clinic center, with BP readings set at 15-minute intervals from 7:00 am to 10:00 pm and 30-min intervals from 10:00 pm to $7 \mathrm{am}$. Twenty-four-hour BP, daytime $\mathrm{BP}$, and nighttime BP were defined as the mean value of $\mathrm{BP}$ readings during a 24-h cycle, daytime, and nighttime, respectively. Valid measurement was regarded as successful documentation of at least $70 \%$ of BP readings taken during a 24-h period. CBP and ABP measurements were taken from the non-dominant arm with an appropriate cuff size.

\section{Definition of blood pressure patterns}

We grouped the patients according to two criteria as follows. (1) In criterion A, conventional criteria based on CBP and 24-h ABP were used as follows: NT, with $\mathrm{CBP}<140 / 90 \mathrm{~mm} \mathrm{Hg}$ and 24-h $\mathrm{ABP}<130 / 80 \mathrm{~mm}$ $\mathrm{Hg}$; WCH, with $\mathrm{CBP} \geq 140 / 90 \mathrm{~mm} \mathrm{Hg}$ and 24-h $\mathrm{ABP}<130 / 80 \mathrm{~mm} \mathrm{Hg} ; \mathrm{MH}$, with $\mathrm{CBP}<140 / 90 \mathrm{~mm}$ $\mathrm{Hg}$ and 24-h $\mathrm{ABP} \geq 130 / 80 \mathrm{~mm} \mathrm{Hg}$; and $\mathrm{SH}$, with $\mathrm{CBP} \geq 140 / 90 \mathrm{~mm} \mathrm{Hg}$ and $24-\mathrm{h} \mathrm{ABP} \geq 130 / 80 \mathrm{~mm} \mathrm{Hg}$ [13-16]. (2) In criterion $B$, criteria based on CBP and daytime ABP according to the 2017 clinical practice guidelines of the American College of Cardiology (ACC) and the American Heart Association (AHA) were used as follows: NT, with $\mathrm{CBP}<130 / 80 \mathrm{~mm} \mathrm{Hg}$ and daytime $\mathrm{BP}<130 / 80 \mathrm{~mm} \mathrm{Hg}$; $\mathrm{WCH}$, with $\mathrm{CBP} \geq 130 / 80 \mathrm{~mm}$ $\mathrm{Hg}$ and daytime $\mathrm{BP}<130 / 80 \mathrm{~mm} \mathrm{Hg} ; \mathrm{MH}$, with $\mathrm{CBP}<130 / 80 \mathrm{~mm} \mathrm{Hg}$ and daytime $\mathrm{BP} \geq 130 / 80 \mathrm{~mm}$ $\mathrm{Hg}$; and $\mathrm{SH}$, with $\mathrm{CBP} \geq 130 / 80 \mathrm{~mm} \mathrm{Hg}$ and daytime $\mathrm{BP} \geq 130 / 80 \mathrm{~mm} \mathrm{Hg}$ [17].

\section{Definition of renal end-point events}

Renal events were defined as initiation of renal replacement therapy, including dialysis and transplantation. The end-point events were assessed every 3 months, either by phone interviews or routine clinical visits, until 31 December, 2017 in the current analysis. Suspected endpoint events were ascertained by an independent endpoint assessment committee. The follow-up protocol has been described in detail elsewhere [10].

\section{Definition of covariate}

A smoker was defined as a patient who was currently smoking or had ever smoked. Diabetes mellitus was 
defined as fasting plasma glucose levels $\geq 7.0 \mathrm{mmol} / \mathrm{L}$ or a self-reported history of diabetes or current use of anti-diabetes drugs. A history of CVD was defined as past occurrence of myocardial infarction, admittance to a hospital for congestive heart failure, or severe cardiac arrhythmia incidents (resuscitated cardiac arrest, ventricular fibrillation, sustained ventricular tachycardia, paroxysmal ventricular tachycardia, atrial fibrillation or flutter, severe bradycardia, or heart block). Dyslipidemia was defined by the presence of at least one of the following: serum total cholesterol level $\geq 200 \mathrm{mg} / \mathrm{dL}(5.2 \mathrm{mM} / \mathrm{L})$, triglycerides $\geq 150 \mathrm{mg} / \mathrm{dL}(1.7 \mathrm{mM} / \mathrm{L})$, low-density lipoprotein cholesterol $\geq 130 \mathrm{mg} / \mathrm{dL}(3.4 \mathrm{mM} / \mathrm{L})$, and highdensity lipoprotein cholesterol $<40 \mathrm{mg} / \mathrm{dL}(1.0 \mathrm{mM} / \mathrm{L})$, or current use of lipid-lowering drugs. Anemia was defined as hemoglobin levels $<100 \mathrm{~g} / \mathrm{L}$. The glomerular filtration rate (GFR) was estimated from serum creatinine measurements and demographic characteristics by the Chronic Kidney Disease Epidemiology Collaboration equation [18]. Patients were divided into four stages according to the level of estimated GFR (eGFR) as follows: CKD stage $1\left(\geq 90 \mathrm{ml} / \mathrm{min} / 1.73 \mathrm{~m}^{2}\right)$, CKD stage $2\left(60-89 \mathrm{ml} / \mathrm{min} / 1.73 \mathrm{~m}^{2}\right)$, CKD stage $3(30-59 \mathrm{ml} /$ $\left.\mathrm{min} / 1.73 \mathrm{~m}^{2}\right)$, and CKD stage $4\left(15-29 \mathrm{ml} / \mathrm{min} / 1.73 \mathrm{~m}^{2}\right)$ [19].

\section{Statistical analysis}

Continuous variables are presented as means \pm standard deviations, while non-parametric variables are expressed as the median and interquartile ranges (IQR). Frequency and proportions were used for categorical variables. We used one-way ANOVA or the Kruskal-Wallis test to compare continuous variables and the Chi square test to compare categorical variables. Comparison between two groups was performed using the independent sample $T$ test, Mann-Whitney U test, and Chi square test for continuous variables and categorical variables.

The incidence rate of renal events was calculated as the number of events per 1000 patient-years. The cumulative hazard ratio for four BP patterns was calculated by Kaplan-Meier (KM) curves. Log-rank tests were used to compare event rates among groups.

A multivariable Cox proportional hazards regression model was used to investigate the associations between BP patterns and outcomes. Model 1 was adjusted for age (continuous) and sex (male vs. female), body mass index (continuous), smoking (yes vs. no), previous history of CVD (yes vs. no), diabetes (yes vs. no), antihypertension therapy (yes vs. no), albumin (continuous), dyslipidemia (yes vs no), anemia (yes vs no), causes of CKD (glomerulonephritis vs others, diabetic kidney disease vs others), logarithm-transformed urinary protein (continuous), and eGFR (continuous). Further adjustment was performed with clinic systolic BP and 24-h systolic BP (continuous) in model 2, with clinic systolic BP and daytime systolic BP (continuous) in model 3, and with clinic systolic BP and nighttime systolic BP (continuous) in model 4. Results of all regression models are reported as hazards ratios (HRs) and 95\% confidence intervals (CIs). Missing data were filled with means for continuous variables with a normal distribution and with medians for continuous variables with a non-normal distribution, while categorical variables were filled with a separate category. The proportional hazards assumption was assessed by logminus-log plots. Sensitivity analyses were performed by a competing risk model to decrease the competing risk of death before ESRD. The interactions of diabetes and glomerulonephritis $(\mathrm{GN})$ with $\mathrm{WCH}$ on renal outcome were assessed. Additionally, stratified analysis (patients with diabetes vs. patients without diabetes) was performed.

Data were analyzed using SPSS software (version22.0; IBM Corp. Armonk, NY, USA) and SAS System version 9.4 (SAS Institute, Cary, NC, USA). A two-sided $P<0.05$ was considered statistically significant.

\section{Results}

\section{Baseline characteristics}

A total of 1714 patients with CKD were included in the present analysis. The mean age of the study population was $48.9 \pm 13.8$ years and $56.8 \%$ were men. Notably, $24.7 \%$ of patients had diabetes and $9.0 \%$ had a prior history of CVD. A total of $76.7 \%$ of patients were taking at least one antihypertensive medication. According to criterion A, there were 672 (39.2\%), 81 (4.7\%), 529 (30.9\%), and 432 (25.2\%) patients in the NT, WCH, MH, and SH groups, respectively. The corresponding prevalence changed to $21.4 \%, 16.6 \%, 13.4 \%$, and $48.6 \%$ according to criterion B in the NT, $\mathrm{WCH}, \mathrm{MH}$, and $\mathrm{SH}$ groups, respectively (Fig. 1).

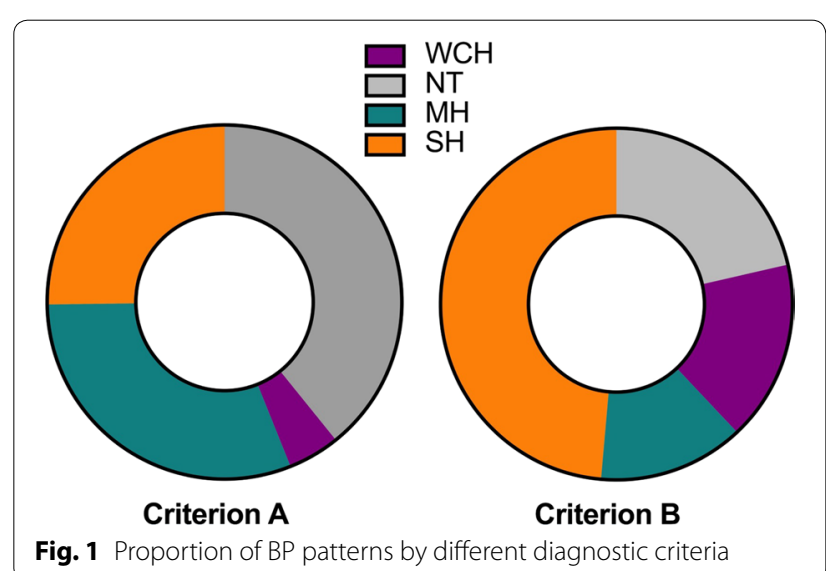


The baseline characteristics of the participants according to their BP pattern as defined by criterion A are shown in Table 1. Participants in the $\mathrm{WCH}, \mathrm{MH}$, and SH groups were older, had a higher body mass index and urinary protein excretion, had a higher prevalence of diabetes and antihypertensive treatment, and had a lower eGFR compared with those in the NT group (all $\mathrm{p}<0.05$ ). Similar characteristics were observed when patients were grouped by criterion B (Additional file 1: Table S3).

BP parameters are shown in Table 2. According to criterion A, 24-h, daytime, and nighttime systolic BP values were significantly higher in the $\mathrm{WCH}, \mathrm{MH}$, and $\mathrm{SH}$ groups compared with the NT group (all $\mathrm{p}<0.05$ ). According to criterion $\mathrm{B}$, not only systolic $\mathrm{BP}$ values, but also 24-h, daytime, and nighttime diastolic BP values were significantly higher in the $\mathrm{WCH}, \mathrm{MH}$, and $\mathrm{SH}$ groups compared with the NT group (all $\mathrm{p}<0.05$ ).

\section{Survival analysis}

The participants were followed up for a total of 7590 years (median: 4.8 years; IQR: $4.0-5.5$ years) for renal events. During this period, 286 participants experienced renal

Table 1 Baseline characteristic of participants according to different BP patterns diagnosed by criterion A

\begin{tabular}{|c|c|c|c|c|c|c|}
\hline & Total $(\mathrm{N}=1714)$ & NT $(\mathrm{N}=672)$ & $\mathrm{WCH}(\mathrm{N}=81)$ & $\mathrm{MH}(\mathrm{N}+(\mathrm{N}=529)$ & $\mathrm{SH}(\mathrm{N}=432)$ & $P$ \\
\hline Age (years) & $48.9 \pm 13.8$ & $46.7 \pm 14.4$ & $53.1 \pm 14.4^{\mathrm{a}}$ & $49.9 \pm 12.8^{\mathrm{ab}}$ & $50.0 \pm 13.3^{\mathrm{ab}}$ & $<0.001$ \\
\hline Male, n (\%) & $974(56.8 \%)$ & $321(47.8 \%)$ & $38(46.9 \%)$ & $318(60.1 \%)^{a b}$ & $297(68.8 \%)^{a b c}$ & $<0.001$ \\
\hline BMI $\left(\mathrm{kg} / \mathrm{m}^{2}\right)$ & $24.6 \pm 3.9$ & $23.9 \pm 3.6$ & $25.0 \pm 4.0^{\mathrm{a}}$ & $24.8 \pm 3.8^{\mathrm{a}}$ & $25.6 \pm 4.1^{\mathrm{ac}}$ & $<0.001$ \\
\hline Smokers, n (\%) & $623(36.8 \%)$ & $188(28.2 \%)$ & $24(30.8 \%)$ & $213(40.7 \%)^{a}$ & $198(46.7 \%)^{a b c}$ & $<0.001$ \\
\hline DM, n (\%) & $366(24.7 \%)$ & $94(16.5 \%)$ & $18(26.1 \%)^{\mathrm{a}}$ & $123(26.9 \%)^{a}$ & $131(34.2 \%)^{a b c}$ & $<0.001$ \\
\hline CVD history, n (\%) & $155(9.0 \%)$ & $41(6.1 \%)$ & $12(14.8 \%)$ & $55(10.4 \%)$ & 47 (10.9\%) & 0.004 \\
\hline Anti-hypertension, n (\%) treatment & $1245(76.7 \%)$ & $380(61.8 \%)$ & $66(85.7 \%)^{\mathrm{a}}$ & $422(81.8 \%)^{\mathrm{a}}$ & $377(90.8 \%)^{\mathrm{ac}}$ & $<0.001$ \\
\hline Causes of CKD* & & & & & & $<0.001$ \\
\hline DKD & $212(12.4 \%)$ & $35(5.2 \%)$ & $11(13.6 \%)^{\mathrm{a}}$ & $73(13.8 \%)^{\mathrm{a}}$ & $93(21.5 \%)^{a b c}$ & \\
\hline GN & $1048(61.1 \%)$ & $489(72.8 \%)$ & $40(49.4 \%)^{\mathrm{a}}$ & $313(59.2 \%)^{a}$ & $206(47.7 \%)^{\mathrm{ac}}$ & \\
\hline Others & $442(25.8 \%)$ & $144(21.4 \%)$ & $29(35.8 \%)^{\mathrm{a}}$ & $140(26.5 \%)$ & $129(29.9 \%)^{\mathrm{a}}$ & \\
\hline$A L B(g / L)$ & $38.3 \pm 7.4$ & $38.7 \pm 7.2$ & $39.4 \pm 5.2$ & $38.2 \pm 7.6$ & $37.7 \pm 7.9^{a}$ & 0.1 \\
\hline $\mathrm{FBG}(\mathrm{mmol} / \mathrm{L})$ & $4.9(4.4,5.6)$ & $4.8(4.3,5.4)$ & $5.0(4.5,5.5)$ & $4.9(4.4,5.7)^{\mathrm{a}}$ & $5.0(4.5,5.9)^{\mathrm{a}}$ & 0.004 \\
\hline $\mathrm{HGB}(\mathrm{g} / \mathrm{L})$ & $126.5 \pm 22.4$ & $127.7 \pm 19.55$ & $121.9 \pm 22.2^{a}$ & $126.3 \pm 24.2$ & $125.7 \pm 24.5$ & 0.1 \\
\hline $\mathrm{TG}(\mathrm{mmol} / \mathrm{L})$ & $1.8(1.2,2.5)$ & $1.7(1.2,2.4)$ & $1.8(1.3,2.4)$ & $1.9(1.3,2.6)^{a}$ & $1.9(1.3,2.6)^{a}$ & 0.004 \\
\hline $\mathrm{TC}(\mathrm{mmol} / \mathrm{L})$ & $4.7(3.9,5.7)$ & $4.7(3.9,5.7)$ & $4.6(3.8,5.5)$ & $4.7(3.9,5.6)$ & $4.7(3.9,5.7)$ & 0.8 \\
\hline HDLC (mmol/L) & $1.1(0.9,1.3)$ & $1.1(0.9,1.4)$ & $1.0(0.9,1.3)$ & $1.0(0.9,1.3)^{\mathrm{a}}$ & $1.1(0.9,1.2)^{\mathrm{a}}$ & 0.001 \\
\hline LDLC (mmol/L) & $2.6(2.1,3.2)$ & $2.6(2.1,3.2)$ & $2.6(2.1,3.2)$ & $2.5(2.1,3.2)$ & $2.7(2.2,3.3)$ & 0.5 \\
\hline $\mathrm{Cr}(\mu \mathrm{mol} / \mathrm{L})$ & $98(141,198)$ & $116.0(80.0,164.2)$ & $153.0(106.7,218.4)^{\mathrm{a}}$ & $151.0(108.0,204.5)^{a}$ & $167.0(122.0,243.2)^{\mathrm{ac}}$ & $<0.001$ \\
\hline $\mathrm{eGFR}\left(\mathrm{mL} / \mathrm{min} / 1.73 \mathrm{~m}^{2}\right)$ & $52.2 \pm 30.1$ & $62.9 \pm 32.7$ & $43.3 \pm 24.3^{a}$ & $48.2 \pm 28.2^{a}$ & $42.2 \pm 23.3^{\mathrm{ac}}$ & $<0.001$ \\
\hline 24 h-Upro (g/L) & $1.0(0.4,2.4)$ & $0.7(0.3,1.5)$ & $1.0(0.4,2.9)^{a}$ & $1.1(0.4,2.5)^{a}$ & $1.8(0.8,3.5)^{a b c}$ & $<0.001$ \\
\hline CKD stages, n (\%) & & & & & & $<0.001$ \\
\hline 1 & $256(14.9 \%)$ & 174 (25.9\%) & $5(6.2 \%)^{a}$ & $55(10.4 \%)^{a}$ & $22(5.1 \%)^{\mathrm{ac}}$ & \\
\hline 2 & 305 (17.8\%) & $144(21.4 \%)$ & $11(13.6 \%)$ & $90(17.0 \%)$ & $60(13.9 \%)^{\mathrm{a}}$ & \\
\hline 3 & $676(39.5 \%)$ & 228 (33.9\%) & $36(44.4 \%)$ & $220(41.6 \%)^{a}$ & $192(44.5 \%)^{a}$ & \\
\hline 4 & 477 (27.8\%) & $126(18.8 \%)$ & $29(35.8 \%)^{\mathrm{a}}$ & $164(31.0 \%)^{a}$ & $158(36.6 \%)^{a}$ & \\
\hline
\end{tabular}

BP blood pressure, NT normal BP, WCH white-coat hypertension, $M H$ masked hypertension, SH sustained hypertension, $B M I$ Body mass index, GN glomerulonephritis, $D K D$ diabetic kidney disease, $A L B$ serum albumin, $F B G$ fasting blood glucose, $D M$ diabetes mellitus, $H G B$ hemoglobin, $T G$ triglyceride, $T C$ total cholesterol, $H D L C$ highdensity lipoprotein cholesterol, LDLC low-density lipoprotein cholesterol, Cr creatinine, eGFR estimated glomerular filtration rate, 24 - Upro 24 -hour urinary protein, CKD chronic kidney disease, CVD cardiovascular disease

Missing counts: BMI 4, ALB 243, smoker 22, CVD history 7, antihypertension treatment: 91, Causes of CKD 12, DM 273, FBG 271, HGB 109, TG 311, TC 311, HDLC 352, LDLC 351, and 24 h-Upro 90

* The diagnosis was made mainly basing on medical history and clinical features, with only 578 patients having renal biopsy confirmation. Among them, 513 patients were diagnosed as GN. IgAN constituted the majority of GN group (54.2\%), following by mesangial proliferative glomerulonephritis ( $32.2 \%)$ and membranous nephropathy (10.5\%). Others group included hypertensive nephropathy, tubulointerstitial nephritis, and cause unknown etc

a $P<0.05$ comparison with NT

b $P<0.05$ comparison with WCH

c $P<0.05$ comparison with $\mathrm{MH}$ 
Table 2 Clinical and ambulatory BP parameters of patients

\begin{tabular}{|c|c|c|c|c|c|c|}
\hline & Total $(\mathrm{N}=1714)$ & NT $(\mathrm{N}=672)$ & $\mathrm{WCH}(\mathrm{N}=83)$ & $\mathrm{MH}(\mathrm{N}=538)$ & $\mathrm{SH}(\mathrm{N}=435)$ & $P$ \\
\hline \multicolumn{7}{|l|}{ Criterion A } \\
\hline Clinic SBP (mmHg) & $129.5 \pm 17.3$ & $118.6 \pm 11.1$ & $143.1 \pm 13.4^{\mathrm{a}}$ & $124.9 \pm 9.4^{\mathrm{ab}}$ & $149.4 \pm 14.6^{\mathrm{abc}}$ & $<0.001$ \\
\hline Clinic DBP $(\mathrm{mmHg})$ & $80.6 \pm 10.4$ & $74.8 \pm 7.4$ & $87.9 \pm 9.1^{\mathrm{a}}$ & $78.6 \pm 6.5^{\mathrm{ab}}$ & $90.8 \pm 10.5^{\mathrm{abc}}$ & $<0.001$ \\
\hline $24 \mathrm{~h}-\mathrm{SBP}(\mathrm{mmHg})$ & $128.3 \pm 17.0$ & $114.5 \pm 8.3$ & $118.3 \pm 7.3^{\mathrm{a}}$ & $134.8 \pm 13.0^{\mathrm{ab}}$ & $143.6 \pm 15.0^{\mathrm{abc}}$ & $<0.001$ \\
\hline 24 h-DBP (mmHg) & $79.3 \pm 10.8$ & $70.9 \pm 6.0$ & $70.6 \pm 5.9$ & $84.5 \pm 8.2^{\mathrm{ab}}$ & $87.4 \pm 10.0^{\mathrm{abc}}$ & $<0.001$ \\
\hline D-SBP $(\mathrm{mmHg})$ & $131.1 \pm 17.0$ & $116.7 \pm 8.9$ & $120.4 \pm 7.5^{\mathrm{a}}$ & $136.4 \pm 13.1^{\mathrm{ab}}$ & $145.1 \pm 15.3^{\mathrm{abc}}$ & $<0.001$ \\
\hline D-DBP (mmHg) & $80.7 \pm 11.0$ & $72.6 \pm 6.3$ & $72.3 \pm 6.3$ & $85.8 \pm 8.5^{\mathrm{ab}}$ & $88.6 \pm 10.5^{\mathrm{abc}}$ & $<0.001$ \\
\hline $\mathrm{N}-\mathrm{SBP}(\mathrm{mmHg})$ & $123.6 \pm 18.7$ & $109.6 \pm 10.0$ & $113.9 \pm 10.5^{\mathrm{a}}$ & $130.4 \pm 15.1^{\mathrm{ab}}$ & $138.9 \pm 17.7^{\mathrm{abc}}$ & $<0.001$ \\
\hline $\mathrm{N}-\mathrm{DBP}(\mathrm{mmHg})$ & $75.4 \pm 12.5$ & $66.7 \pm 7.5$ & $66.6 \pm 9.3$ & $80.6 \pm 11.1^{\mathrm{ab}}$ & $84.1 \pm 11.1^{1 \mathrm{abc}}$ & $<0.001$ \\
\hline \multicolumn{7}{|l|}{ Criterion B } \\
\hline Clinic SBP (mmHg) & $129.5 \pm 17.3$ & $113.4 \pm 9.7$ & $131.6 \pm 12.0^{\mathrm{a}}$ & $117.4 \pm 8.9^{\mathrm{ab}}$ & $139.1 \pm 15.9^{\mathrm{abc}}$ & $<0.001$ \\
\hline Clinic DBP (mmHg) & $80.6 \pm 10.4$ & $70.7 \pm 6.2$ & $83.4 \pm 7.0^{\mathrm{a}}$ & $73.0 \pm 5.5^{\mathrm{ab}}$ & $86.2 \pm 9.5^{\mathrm{abc}}$ & $<0.001$ \\
\hline 24 h-SBP (mmHg) & $128.3 \pm 17.0$ & $112.0 \pm 8.3$ & $116.7 \pm 8.0^{\mathrm{a}}$ & $131.5 \pm 12.3^{\mathrm{ab}}$ & $138.6 \pm 15.2^{\mathrm{abc}}$ & $<0.001$ \\
\hline 24 h-DBP (mmHg) & $79.3 \pm 10.8$ & $69.0 \pm 5.9$ & $71.7 \pm 5.8^{\mathrm{a}}$ & $81.7 \pm 8.1^{\mathrm{ab}}$ & $85.7 \pm 9.5^{\mathrm{abc}}$ & $<0.001$ \\
\hline D-SBP (mmHg) & $131.1 \pm 17.0$ & $113.8 \pm 8.3$ & $117.7 \pm 7.3^{\mathrm{a}}$ & $133.8 \pm 12.2^{\mathrm{ab}}$ & $140.4 \pm 15.1^{\mathrm{abc}}$ & $<0.001$ \\
\hline D-DBP (mmHg) & $80.7 \pm 11.0$ & $70.5 \pm 5.9$ & $72.6 \pm 5.4^{\mathrm{a}}$ & $83.7 \pm 8.0^{\mathrm{ab}}$ & $87.1 \pm 9.6^{\mathrm{abc}}$ & $<0.001$ \\
\hline $\mathrm{N}-\mathrm{SBP}(\mathrm{mmHg})$ & $123.6 \pm 18.7$ & $107.5 \pm 10.8$ & $113.5 \pm 10.8^{\mathrm{a}}$ & $125.4 \pm 14.4^{\mathrm{ab}}$ & $133.6 \pm 17.8^{\mathrm{abc}}$ & $<0.001$ \\
\hline $\mathrm{N}-\mathrm{DBP}(\mathrm{mmHg})$ & $75.4 \pm 12.5$ & $64.9 \pm 7.5$ & $69.0 \pm 7.9^{\mathrm{a}}$ & $76.9 \pm 9.7^{\mathrm{ab}}$ & $81.9 \pm 10.7^{\mathrm{abc}}$ & $<0.001$ \\
\hline
\end{tabular}

Abbreviation: 24h-SBP: 24-hour average ambulatory systolic blood pressure, 24h-DBP: 24-hour average ambulatory diastolic blood pressure, D-SBP: daytime systolic blood pressure, D-DBP: daytime diastolic blood pressure, N-SBP: nighttime systolic blood pressure, N-DBP: nighttime diastolic blood pressure

Table 3 Incidence of renal events by different BP patterns

\begin{tabular}{lrrr}
\hline BP patterns & Number of events & Median follow-up & $\begin{array}{l}\text { Events per 1000 person- } \\
\text { years }\end{array}$ \\
\hline Criterion A & & & \\
NT $(n=672)$ & $39(5.80 \%)$ & $5.1(4.3,5.6)$ & 12.08 \\
WCH $(n=81)$ & $18(22.22 \%)$ & $4.9(3.7,5.6)$ & 49.58 \\
MH $(n=529)$ & $111(20.98 \%)$ & $4.6(3.7,5.5)$ & 49.07 \\
SH $(n=432)$ & $118(27.31 \%)$ & $4.5(2.7,5.4)$ & 67.96 \\
Total & $286(16.69 \%)$ & $4.8(4.0,5.5)$ & 37.68 \\
Criterion B & & & \\
NT $(n=367)$ & $17(4.63 \%)$ & $5.1(4.3,5.6)$ & 9.52 \\
WCH $(n=284)$ & $35(12.32 \%)$ & $5.0(4.1,5.5)$ & 26.51 \\
MH $(n=230)$ & $42(18.26 \%)$ & $4.8(4.0,5.6)$ & 40.81 \\
SH $(n=833)$ & $192(23.05 \%)$ & $4.5(3.4,5.4)$ & 55.57 \\
Total & $286(16.69 \%)$ & $4.8(4.0,5.5)$ & 37.68 \\
\hline
\end{tabular}

BP blood pressure, $N T$ normal BP, $W C H$ white-coat hypertension, $M H$ masked hypertension, $S H$ sustained hypertension

event, corresponding to an incidence rate of 37.68 per 1000 person-years. The incidence rate for each BP pattern is shown in Table 3.

Patients in the $\mathrm{WCH}, \mathrm{MH}$, and $\mathrm{SH}$ groups had a higher incidence rates of renal events compared with those in the NT group (Fig. 2). Cox analysis showed that patients in the $\mathrm{WCH}, \mathrm{MH}$, and $\mathrm{SH}$ groups had a greater risk for renal event, with adjusted HRs of 2.38 (95\% CI 1.34-4.23), 2.13 (95\% CI 1.45-3.11), and 2.02 (95\% CI
1.36-3.00), respectively, as compared with those in NT group by criterion A (Table 4). Similar results were observed by criterion B, with adjusted HRs for the $\mathrm{WCH}$, $\mathrm{MH}$, and $\mathrm{SH}$ groups of 1.98 (95\% CI 1.10--3.58), 2.24 (95\% CI 1.25-3.99), and 2.04 (95\% CI 1.21-3.41), respectively (Table 5). The HRs remained significant after further adjustments for clinic systolic BP and 24-h systolic BP, clinic systolic BP and daytime systolic BP, and clinic systolic BP and nighttime systolic BP (Table 4 and 
a Criterion A

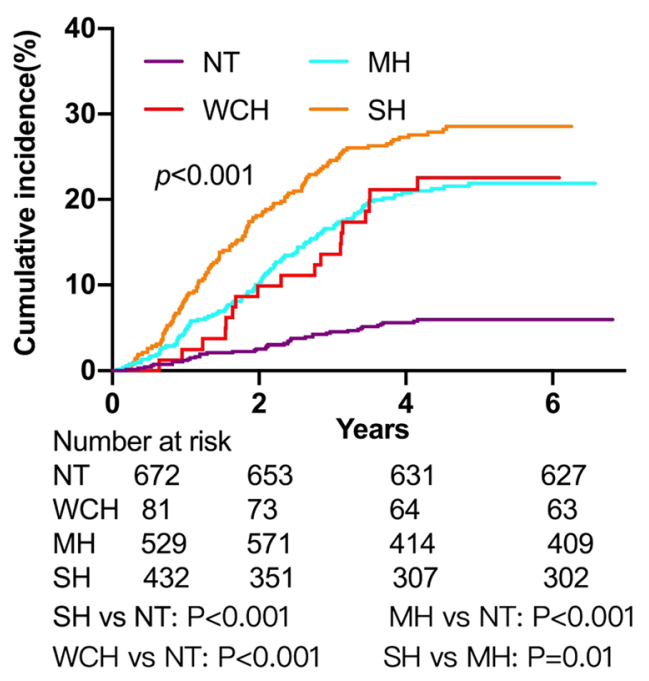

Fig. 2 Kaplan-Meier hazard curve for renal events by BP patterns b Criterion B

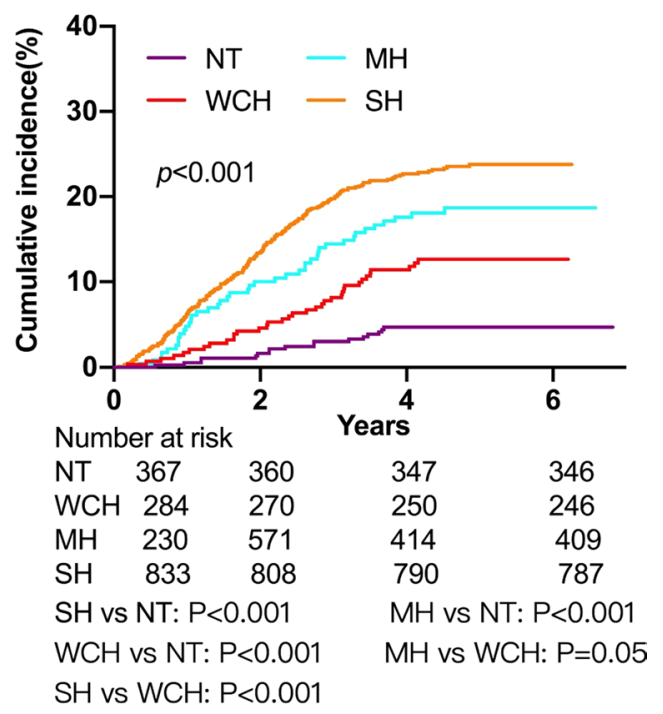

Table 5). Sensitivity analyses for decreasing the competing risk of death before ESRD showed consistent results (Additional file 1: Table S4). No interaction between WCH and GN was found ( $P$ for criterion A: 0.73 and $P$ for criterion B: 0.15 , respectively). Stratified analysis of the effect of $\mathrm{WCH}$ on renal event in patients with diabetes compared with those without diabetes was shown in Additional file 1: Figure S1.

\section{Discussion}

In the present prospective cohort study, patients with CKD stages 1-4 were enrolled and followed for a median duration of 4.8 years to investigate the role of the BP pattern for renal prognosis in patients with CKD. We found that $\mathrm{WCH}$, in addition to $\mathrm{MH}$ and $\mathrm{SH}$, were associated with an increased risk for renal events in non-dialysis dependent Chinese patients with CKD. This finding suggests that $\mathrm{WCH}$ should not be regarded as irrelevant in clinical practice.

With the introduction of ABP monitoring to clinical practice, four BP patterns have been defined according to the combination of both $\mathrm{CBP}$ and ABP readings. The prevalence of $\mathrm{WCH}$ in patients with $\mathrm{CKD}$ varied in different studies, ranging from $2.3 \%$ in the African American Study of Kidney Disease and Hypertension (AASK) study [20], $11 \%$ in the German Chronic Kidney Disease (GCKD) study [6], and 31.7\% in a Italian study [21]. This difference between studies could be partly ascribed to different classification criteria adopted in different studies, in addition to some specific features, such as race, genetics, etiology of CKD, and comorbidities, of each cohort.
The present study showed that the prevalence of $\mathrm{WCH}$ was $4.7 \%$ when diagnosed by criterion A. This finding is similar to that of $4.1 \%$ in the Chronic Renal Insufficiency Cohort (CRIC) Study [4] and 5.6\% in the Chronic Kidney Disease Japan Cohort (CKD-JAC) [22], which used the same diagnostic criteria as our study. When AHA/ACC criteria were adopted, the prevalence of $\mathrm{WCH}$ increased to $16.6 \%$ in the present study, accompanied by corresponding changes in prevalence of $\mathrm{NT}, \mathrm{MH}$, and $\mathrm{SH}$.

Unlike $\mathrm{MH}$ and $\mathrm{SH}$, which have been proven to have adverse effects on prognosis in patients with CKD, the effect of $\mathrm{WCH}$ on long-term prognosis of patients with CKD is still controversial [23, 24]. A subgroup analysis of 4346 patients with CKD from the HONEST study showed that patients with $\mathrm{WCH}$ had an increased cardiovascular risk [7]. However, a multicenter cohort study from Italy of 489 patients with CKD that followed patients for a median of 9 months and a single center study of 588 patients with CKD that followed patients for a median of 35 months from Guangzhou, China showed that $\mathrm{WCH}$ did not result in adverse prognosis of renal and cardiovascular outcomes $[8,9]$. In the present study with more patients enrolled and a longer follow-up period than these previous studies, we found a significant association between $\mathrm{WCH}$ and renal events. The risk for renal event in participants with $\mathrm{WCH}$, as defined by either conventional criteria or AHA/ACC criteria, was significantly greater than that of participants with normal BP after full adjustment for relevant confounders. Taken together, these results indicate that $\mathrm{WCH}$ may have pathophysiological relevance with the prognosis of CKD. 
Table 4 Hazard ratio for renal events by different BP patterns by criteria A

\begin{tabular}{|c|c|c|c|c|c|}
\hline & $\begin{array}{l}\text { Unadjusted } \\
\mathrm{HR}(95 \% \mathrm{Cl})\end{array}$ & $\begin{array}{l}\text { Model } 1 \\
\text { HR }(95 \% \mathrm{Cl})\end{array}$ & $\begin{array}{l}\text { Model } 2 \\
\text { HR }(95 \% \mathrm{Cl})\end{array}$ & $\begin{array}{l}\text { Model } 3 \\
\text { HR }(95 \% \mathrm{Cl})\end{array}$ & $\begin{array}{l}\text { Model } 4 \\
\text { HR }(95 \% \mathrm{Cl})\end{array}$ \\
\hline \multicolumn{6}{|l|}{ BP patterns } \\
\hline NT & 1.00 (ref) & 1.00 (ref) & 1.00 (ref) & 1.00 (ref) & 1.00 (ref) \\
\hline WCH & $4.07(2.32,7.11)$ & $2.38(1.34,4.23)$ & $2.36(1.29,4.34)$ & $2.37(1.29,4.35)$ & $2.38(1.30,4.37)$ \\
\hline $\mathrm{MH}$ & $3.98(2.76,5.73)$ & $2.13(1.45,3.11)$ & $2.25(1.48,3.41)$ & $2.23(1.47,3.37)$ & $2.20(1.47,3.30)$ \\
\hline $\mathrm{SH}$ & $5.52(3.85,7.93)$ & $2.02(1.36,3.00)$ & $2.15(1.27,3.63)$ & $2.12(1.27,3.57)$ & $2.11(1.26,3.54)$ \\
\hline Clinic SBP (per 10 mm Hg) & $1.28(1.21,1.35)$ & - & $1.01(0.91,1.11)$ & $1.01(0.91,1.11)$ & $1.00(0.91,1.11)$ \\
\hline 24 h-SBP (per 10 mm Hg) & $1.32(1.24,1.39)$ & - & $0.97(0.88,1.07)$ & - & - \\
\hline D-SBP (per 10 mm Hg) & $1.31(1.23,1.38)$ & - & - & $0.98(0.89,1.07)$ & - \\
\hline N-SBP (per 10 mm Hg) & $1.30(1.23,1.36)$ & - & - & - & $0.98(0.90,1.07)$ \\
\hline Age & $1.00(0.99,1.01)$ & $0.99(0.97,0.99)$ & $0.98(0.97,0.99)$ & $0.98(0.97,0.99)$ & $0.98(0.97,0.99)$ \\
\hline Sex (M vs W) & $1.32(1.04,1.68)$ & $1.74(1.25,2.43)$ & $1.74(1.25,2.42)$ & $1.74(1.25,2.43)$ & $1.74(1.25,2.42)$ \\
\hline BMI & $0.95(0.92,0.99)$ & $0.97(0.94,1.01)$ & $0.96(0.94,1.01)$ & $0.97(0.94,1.01)$ & $0.98(0.94,1.01)$ \\
\hline Smoker & $1.26(0.99,1.60)$ & $0.87(0.64,1.18)$ & $0.87(0.64,1.19)$ & $0.87(0.64,1.19)$ & $0.87(0.64,1.19)$ \\
\hline DM & $1.79(1.38,2.32)$ & $1.00(0.61,1.63)$ & $1.02(0.62,1.66)$ & $1.01(0.62,1.65)$ & $1.01(0.62,1.66)$ \\
\hline CVD history & $1.34(0.96,1.87)$ & $1.25(0.87,1.79)$ & $1.25(0.86,1.80)$ & $1.25(0.86,1.80)$ & $1.25(0.87,1.80)$ \\
\hline Anti-hypertensive treatment & $0.34(0.23,0.51)$ & $0.66(0.44,1.00)$ & $0.67(0.44,1.01)$ & $0.67(0.44,1.01)$ & $0.66(0.44,1.00)$ \\
\hline Dyslipidemia & $0.92(0.69,1.24)$ & $0.75(0.54,1.02)$ & $0.75(0.54,1.03)$ & $0.75(0.54,1.03)$ & $0.75(0.54,1.03)$ \\
\hline ALB & $0.96(0.95,0.97)$ & $0.96(0.94,0.98)$ & $0.96(0.94,0.98)$ & $0.96(0.94,0.98)$ & $0.96(0.94,0.98)$ \\
\hline Anemia & $3.70(2.83,4.83)$ & $1.33(0.98,1.80)$ & $1.33(0.98,1.82)$ & $1.33(0.98,1.82)$ & $1.33(0.98,1.82)$ \\
\hline IgUpro & $4.51(3.51,5.81)$ & $2.23(1.62,3.08)$ & $2.25(1.63,3.10)$ & $2.25(1.63,3.10)$ & $2.25(1.63,3.10)$ \\
\hline eGFR & $0.94(0.93,0.95)$ & $0.94(0.93,0.95)$ & $0.94(0.93,0.95)$ & $0.94(0.93,0.95)$ & $0.94(0.93,0.95)$ \\
\hline \multicolumn{6}{|l|}{ Causes of CKD } \\
\hline DKD vs others & $2.77(1.99,3.88)$ & $1.73(0.98,3.04)$ & $1.73(0.98,3.04)$ & $1.73(0.98,3.04)$ & $1.74(0.99,3.07)$ \\
\hline GN vs others & $0.95(0.71,1.27)$ & $1.49(1.10,2.04)$ & $1.48(1.08,2.02)$ & $1.48(1.08,2.03)$ & $1.48(1.08,2.03)$ \\
\hline
\end{tabular}

NT normotension, $W C H$ white-coat hypertension, MH masked hypertension, $S H$ sustained hypertension, $H R$ hazard ratio, $C l$ confidence interval, $B M I$ body-mass index, DM diabetes mellitus, CVD history history of CV disease, $A L B$ serum albumin, eGFR estimated glomerular filtration rate, $C K D$ chronic kidney disease, GN glomerulonephritis, DKD diabetic kidney disease

Model 1: adjusted for age, gender, smoker, BMI, DM, CVD history, anti-hypertensive treatment, Dyslipidemia, ALB, Anemia, logarithm transformed 24 h-urine protein eGFR and causes of CKD

Model 2: model 1 + clinic systolic blood pressures and 24-h ambulatory systolic blood pressure

Model 3: model $1+$ clinic systolic blood pressures and daytime systolic blood pressure

Model 4: model 1 + clinic systolic blood pressures and nighttime systolic blood pressure

Patients with $\mathrm{WCH}$ had significantly higher clinical and out-of-office BP values compared with normotensive patients in the present study. The relationship between BP and outcomes shows a continuous relationship, even in the normotensive range. Comparatively small increases in mean BP are associated with substantial differences in risk. Cha et al. showed that 24-h ABP progressively increased with the categories of NT to $\mathrm{WCH}$ to $\mathrm{MH}$ to $\mathrm{SH}$ in 1317 patients with CKD [25], which also found in our cohort. A previous study showed an increased cardiovascular risk in patients with $\mathrm{WCH}$ when $\mathrm{ABP}$ at baseline was markedly higher in the $\mathrm{WCH}$ group than in the NT group [26]. Therefore, this difference in absolute $\mathrm{BP}$ value between patients with $\mathrm{WCH}$ and those with NT might account for, at least in part, the risk of renal events in $\mathrm{WCH}$ in the present study. Different diagnostic criteria might affect the difference in BP values between BP patterns. Only a difference in 24-h and/or daytime systolic BP values was found between the $\mathrm{WCH}$ and NT groups in the above-mentioned Italian and Guangzhou studies. [8,9] However, in the present study, 24-h, daytime, and nighttime systolic BP values in patients with $\mathrm{WCH}$, as diagnosed by either criterion $\mathrm{A}$ or $\mathrm{B}$, were all significantly higher than those in patients with NT. This more marked difference in BP values between the NT and WCH groups of our cohort might explain the discrepancies between our study and the other studies.

In addition to the different criteria of the definition of $\mathrm{WCH}$, some intrinsic factors of each study (e.g., cause and stage of enrolled participants with CKD, race and 
Table 5 Hazard ratio for renal events by different BP patterns by criteria B

\begin{tabular}{|c|c|c|c|c|c|}
\hline & $\begin{array}{l}\text { Unadjusted } \\
\text { HR }(95 \% \mathrm{Cl})\end{array}$ & $\begin{array}{l}\text { Model } 1 \\
\text { HR }(95 \% \mathrm{Cl})\end{array}$ & $\begin{array}{l}\text { Model } 2 \\
\text { HR (95\% CI) }\end{array}$ & $\begin{array}{l}\text { Model } 3 \\
\text { HR }(95 \% \mathrm{Cl})\end{array}$ & $\begin{array}{l}\text { Model } 4 \\
\text { HR (95\% CI) }\end{array}$ \\
\hline \multicolumn{6}{|l|}{ BP patterns } \\
\hline NT & 1.00 (ref) & 1.00 (ref) & 1.00 (ref) & 1.00 (ref) & 1.00 (ref) \\
\hline WCH & $2.76(1.55,4.92)$ & $1.98(1.10,3.58)$ & $1.90(1.04,3.49)$ & $1.90(1.04,3.50)$ & $1.90(1.04,3.49)$ \\
\hline $\mathrm{MH}$ & $4.29(2.44,7.53)$ & $2.24(1.25,3.99)$ & $2.23(1.22,4.08)$ & $2.22(1.21,4.08)$ & $2.21(1.22,3.99)$ \\
\hline $\mathrm{SH}$ & $5.69(3.46,9.34)$ & $2.04(1.21,3.41)$ & $1.91(1.08,3.37)$ & $1.91(1.08,3.37)$ & $1.90(1.08,3.33)$ \\
\hline Clinic SBP (per 10 mm Hg) & $1.28(1.21,1.35)$ & - & $1.03(0.94,1.12)$ & $1.02(0.94,1.12)$ & $1.02(0.94,1.11)$ \\
\hline 24 h-SBP (per 10 mm Hg) & $1.32(1.24,1.39)$ & - & $1.00(0.91,1.10)$ & - & - \\
\hline D-SBP (per 10 mm Hg) & $1.31(1.23,1.38)$ & - & - & $1.00(0.92,1.10)$ & - \\
\hline N-SBP (per 10 mm Hg) & $1.30(1.23,1.36)$ & - & - & - & $1.01(0.93,1.10)$ \\
\hline Age & $1.00(0.99,1.01)$ & $0.98(0.97,0.99)$ & $0.98(0.97,0.99)$ & $0.98(0.97,0.99)$ & $0.98(0.97,0.99)$ \\
\hline Sex (M vs W) & $1.32(1.04,1.68)$ & $1.79(1.29,2.50)$ & $1.78(1.28,2.48)$ & $1.78(1.28,2.48)$ & $1.78(1.28,2.48)$ \\
\hline BMI & $0.95(0.92,0.99)$ & $0.98(0.95,1.01)$ & $0.98(0.94,1.01)$ & $0.98(0.94,1.01)$ & $0.98(0.94,1.01)$ \\
\hline Smoker & $1.26(0.99,1.60)$ & $0.88(0.64,1.19)$ & $0.88(0.64,1.20)$ & $0.88(0.64,1.20)$ & $0.88(0.64,1.20)$ \\
\hline $\mathrm{DM}$ & $1.79(1.38,2.32)$ & $1.00(0.61,1.62)$ & $1.00(0.61,1.63)$ & $1.00(0.61,1.63)$ & $0.99(0.61,1.63)$ \\
\hline CVD history & $1.34(0.96,1.87)$ & $1.27(0.88,1.83)$ & $1.28(0.89,1.84)$ & $1.28(0.89,1.84)$ & $1.28(0.88,1.84)$ \\
\hline Anti-hypertensive treatment & $0.34(0.23,0.51)$ & $0.63(0.42,0.96)$ & $0.64(0.42,0.97)$ & $0.64(0.42,0.97)$ & $0.64(0.42,0.97)$ \\
\hline Dyslipidemia & $0.92(0.69,1.24)$ & $0.73(0.53,1.00)$ & $0.73(0.53,1.00)$ & $0.73(0.53,1.00)$ & $0.73(0.53,1.00)$ \\
\hline ALB & $0.96(0.95,0.97)$ & $0.96(0.94,0.98)$ & $0.96(0.94,0.98)$ & $0.96(0.94,0.98)$ & $0.96(0.94,0.98)$ \\
\hline Anemia & $3.70(2.83,4.83)$ & $1.36(1.00,1.84)$ & $1.34(0.99,1.82)$ & $1.34(0.99,1.82)$ & $1.34(0.99,1.82)$ \\
\hline IgUpro & $4.51(3.51,5.81)$ & $2.33(1.69,3.22)$ & $2.31(1.67,3.19)$ & $2.31(1.67,3.19)$ & $2.30(1.66,3.19)$ \\
\hline eGFR & $0.94(0.93,0.95)$ & $0.94(0.93,0.95)$ & $0.94(0.93,0.95)$ & $0.94(0.93,0.95)$ & $0.94(0.93,0.95)$ \\
\hline \multicolumn{6}{|l|}{ Causes of CKD } \\
\hline DKD vs others & $2.77(1.99,3.88)$ & $1.73(0.98,3.05)$ & $1.73(0.98,3.05)$ & $1.73(0.98,3.05)$ & $1.73(0.98,3.05)$ \\
\hline GN vs others & $0.95(0.71,1.27)$ & $1.44(1.06,1.96)$ & $1.48(1.08,2.03)$ & $1.48(1.08,2.03)$ & $1.48(1.08,2.03)$ \\
\hline
\end{tabular}

NT normotension, $W C H$ white-coat hypertension, $M H$ masked hypertension, $S H$ sustained hypertension, $H R$ hazard ratio, $C l$ confidence interval, $B M I$ body-mass index, DM diabetes mellitus, CVD history history of CV disease, $A L B$ serum albumin, eGFR estimated glomerular filtration rate, $C K D$ chronic kidney disease, GN glomerulonephritis, DKD diabetic kidney disease

Model 1: adjusted for age, gender, smoker, BMI, DM, CVD history, anti-hypertensive treatment, Dyslipidemia, ALB, Anemia, logarithm transformed 24 h-urine protein, eGFR and causes of CKD

Model 2: model 1 + clinic systolic blood pressures and 24-h ambulatory systolic blood pressure

Model 3: model $1+$ clinic systolic blood pressures and daytime systolic blood pressure

Model 4: model 1 + clinic systolic blood pressures and nighttime systolic blood pressure

ethnicity of the study population, presence of concomitant additional cardiovascular risk factors, treatment status, and follow-up length), might also contribute to the inconsistency in $\mathrm{WCH}$ values on prognosis. [27] For instance, the most common cause of CKD in the Italian study was hypertensive nephropathy [8], which accounted for $44.6 \%$ of the cohort, and $9.2 \%$ had GN. In our study, GN constituted the majority (61.1\%) of the cohort, while hypertensive nephropathy, together with other/unknown causes, accounted for $25.8 \%$ as shown in Table 1. GN was independently associated with renal progression in the present study, but no interaction between GN and WCH was found. We admitted that the diagnosis of CKD causes was mainly made according to medical history and clinical features with only a few having renal biopsy confirmation. The possibility of some kind of misclassification, therefore, could not be excluded. Whether the cause of CKD plays a role in the association of $\mathrm{WCH}$ with progression of CKD remains undefined and requires further study. Additionally, the prevalence of a previous history of CVD and diabetes was $9 \%$ and $24.7 \%$ in our cohort, respectively, which is markedly lower than that in well-known Western CKD cohorts $(30.3 \%$ and $36 \%$, respectively in the Italian cohort [8]; $34 \%$ and $46 \%$, respectively in CRIC study [4]; and $32 \%$ and $35 \%$, respectively in the GCKD study [6]). Since the magnitude of association of CKD with its risk factors is somewhat different between cohorts [28], this difference in prevalence of risk factors between cohorts might also affect the association of $\mathrm{WCH}$ with progression of CKD.

This study has some limitations. First, ABP monitoring was only performed once at enrollment. The BP pattern 
might have changed during follow-up as found in the ELSA study. [29] Furthermore, the APrODiTe-2 study showed that an adverse change (sustained uncontrolled or masked hypertension) of the BP pattern was associated with a change in the eGFR [30]. Therefore, the possibility that patients with $\mathrm{WCH}$ and renal events in our cohort might have had their BP pattern changed during follow-up cannot be excluded. Second, not all enrolled patients received ABP monitoring, which is not a mandatory requirement for enrollment of the cohort. This might have resulted in population selection bias. However, patients who were included in the present analysis with ABP data were younger and had high level of eGFR than those who were excluded with a comparable level of urine protein. The presence of these features in patients who were included meant that they had a lower risk of renal progression compared with those who were excluded. Third, although our multivariable analyses included careful adjustment for covariates, we cannot exclude the possibility of residual confounding from other unrecorded covariates that were not ascertained. Forth, doubling of serum creatinine and a rise in proteinuria are also established surrogate renal end-points, which might further refine the effect of hypertension pattern. However, these data were not included in the present analysis. Finally, the cohort comprised only Chinese patients with CKD. As mentioned above, our cohort may have different causes and prevalence of comorbidity of CKD, as well as different ethnic, environmental, and treatment factors, compared with other CKD cohorts from Western countries. Therefore, our results might not be able to be directly extrapolated to other patient populations.

\section{Conclusions}

In conclusion, our study provides evidence that $\mathrm{WCH}$ is associated with a greater risk for renal events in non-dialysis dependent Chinese patients with CKD. Future prospective, randomized clinical trials are required to clarify whether treating $\mathrm{WCH}$ can delay progression of renal disease in patients with CKD.

\section{Supplementary information}

Supplementary information accompanies this paper at https://doi. org/10.1186/s12967-020-02413-w.

Additional file 1: Table S1. The inclusion and exclusion criteria of C-STRIDE study. Table S2. Comparison of baseline characteristics between included and excluded participants in the current study. Table S3. Baseline characteristic of participants according to different BP patterns diagnosed by criterion B. Table S4. Hazard ratio for renal events by different BP patterns in competing risk model. Figure S1. Stratified analysis of the effect of WCH on renal event in patients with diabetes compared with those without diabetes.

\section{Abbreviations}

CKD: Chronic kidney disease; BP: Blood pressure; CBP: Clinical BP; ABP: Ambulatory BP; NT: Normal BP; WCH: White coat hypertension; MH: Masked hypertension; SH: Sustained hypertension; ESRD: End stage of renal disease; CVD: Cardiovascular disease; eGFR: Estimated glomerular filtration rate; C-STRIDE: The Chinese Cohort Study of Chronic Kidney Disease; GCKD: German Chronic Kidney Disease; CRIC: The Chronic Renal Insufficiency Cohort; CKD-JAC: The Chronic Kidney Disease Japan Cohort; ACC: American College of Cardiology; AHA: American Heart Association; IQR: interquartile ranges; KM: Kaplan-Meier; HR: Hazards ratio; Cl: Confidence interval.

\section{Acknowledgements}

The authors would like to express gratitude to every member of the CSTRIDE group for their collaboration.

We thank Ellen Knapp, PhD, from Liwen Bianji, Edanz Group China (http://www.liwenbianji.cn/ac), for editing the English text of a draft of this manuscript.

The Chinese Cohort Study of Chronic Kidney Disease (C-STRIDE) Collaborators.

Peking University First Hospital: Ming-Hui Zhao, Luxia Zhang; the Affiliated Hospital of Hubei Traditional Chinese Medical College: Xiaoqin Wang, Jun Yuan; the Xiangya Hospital of Central South University: Qiaoling Zhou, Qiongjing Yuan; General Hospital of Ningxia Medical University: Menghua Chen, Xiaoling Zhou; the Second Hospital of Hebei Medical University: Shuxia Fu, Shaomei Li; Guizhou Provincial People's Hospital: Yan Zha, Rongsai Huang; the First Affiliated Hospital of Zhengzhou University: Zhangsuo Liu, JunJun Zhang; Sichuan Academy of Medical Sciences and Sichuan Provincial People's Hospital: Li Wang, Lei Pu; the First Affiliated Hospital of Xinjiang University of Medicine: Jian Liu, Suhua Li; Peking University Shenzhen Hospital: Zuying Xiong, Wei Liang; Xinqiao Hospital: Jinghong Zhao, Jiao Mu; the Second Affiliated Hospital of Kunming Medical College: Xiyan Lian, Yunjuan Liao; the First Affiliated Hospital of Chongqing University of Medicine: Hua Gan, Liping Liao; Shandong Provincial Hospital: Rong Wang, Zhimei Lv; the First Affiliated Hospital of Guangxi University of Medicine: Yunhua Liao, Ling Pan; the First Affiliated Hospital of the Medical College, Shihezi University: Xiaoping Yang, Zhifeng Lin; Yuxi City People's Hospital: Zongwu Tong, Yun Zhu; Beilun People's Hospital in Ningbo: Qiang He, Fuquan Wu; the Second Affiliated Hospital of Tianjin University of Medicine: Rong Li, Kai Rong; the First Affiliated Hospital of Baotou Medical College: Caili Wang, Yanhui Zhang; Peking University Third Hospital: Yue Wang, Wen Tang; Beijing Hospital of Ministry of Health: Hua Wu, Ban Zhao; the Second Hospital of Shanxi University of Medicine: Rongshan Li, Lihua Wang; Shengjing Hospital of China Medical University: Detian Li, Feng Du; the First Affiliated Hospital of Anhui University of Medicine: Yonggui Wu, Wei Zhang; Tianjin Medical University General Hospital: Shan Lin, Pengcheng Xu; the First Affiliated Hospital of Dalian University of Medicine: Hongli Lin; Shandong University Qilu Hospital: Zhao Hu, Fei Pei; the Affiliated Hospital of Hebei University: Haisong Zhang, Yan Gao; Dongzhimen Hospital Affiliated to Beijing University of Chinese Medicine: Luying Sun, Xia Li; Chifeng Second Hospital: Wenke Wang, Fengling Lv; the Second Affiliated Hospital of Anhui University of Medicine: Deguang Wang, Xuerong Wang; Qianfoshan Hospital: Dongmei Xu, Lijun Tang; China Rehabilitation Research Center, Beijing Boai Hospital: Yingchun Ma, Tingting Wang; West China Hospital of Sichuan University: Ping Fu, Tingli Wang; the First Affiliated Hospital with Nanjing Medical University: Changying Xing, Chengning Zhang; Minhang Central Hospital: Xudong Xu, Haidong He; the Second Affiliated Hospital of Chongqing University of Medicine: Xiaohui Liao, Shuqin Xie; the Affiliated Hospital of Chengde Medical Colledge: Guicai Hu, Lan Huang.

\section{Authors' contributions}

QW searched the literature; QW and JWW analyzed the data, QW and YW interpreted the results and drafted the manuscript. YW and JWW revised the manuscript. YW conceived and design the study, organized and supervised the study, interpreted the results, and revised the manuscript. LXZ and MHZ obtained funding and revised the manuscript. Other members collected and analyzed the data. YW is the guarantor and takes full responsibility for the work as a whole, including the study design, access to data, and the decision to submit and publish the manuscript. All authors read and approved the final manuscript. 


\section{Funding}

This study was supported by grants from the Research Special Fund for Public Welfare Industry of Health from the National Health and Family Planning Commission of the People's Republic of China (No. 201002010); the National Key Technology R\&D Program of the Ministry of Science and Technology (No. 2011BAI10B01), the National Natural Science Foundation of China (9184101, 81771938, 81301296), Beijing Nova Programme Interdisciplinary Cooperation Project (Z191100001119008), the National Key R\&D Program of the Ministry of Science and Technology of China (2016YFC1305400), the University of Michigan Health System-Peking University Health Science Center Joint Institute for Translational and Clinical Research (BMU20160466, BMU2018JI012, BMU2019JI005), and from Peking University (BMU2018MX020, PKU2017LCX05).

\section{Availability of data and materials}

All data generated or analyzed during this study are included in this published article.

\section{Ethics approval and consent to participate}

The study was approved by the Ethics Committee of Peking University First Hospital and was in adherence with the Declaration of Helsinki.

\section{Consent for publication}

Not applicable.

\section{Competing interests}

The authors declare that they have no competing interests.

\section{Author details}

${ }^{1}$ Renal Division, Department of Medicine, Peking University First Hospital, Institute of Nephrology, Peking University, Key Laboratory of Renal Disease, National Health and Family Planning Commission of the People's Republic of China, Key Laboratory of Chronic Kidney Disease Prevention and Treatment, Ministry of Education, Beijing 100034, China. ${ }^{2}$ Center for Data Science in Health and Medicine, Peking University, Beijing, China. ${ }^{3}$ Peking-Tsinghua Center for Life Sciences, Beijing, China.

Received: 18 March 2020 Accepted: 9 June 2020

Published online: 15 June 2020

\section{References}

1. Webster AC, Nagler EV, Morton RL, Masson P. Chronic kidney disease. Lancet. 2017;389:1238-52.

2. Verdecchia P, Angeli F, Bartolini C, Reboldi G. Twenty-four hour ambulatory blood pressure monitoring to all? Comments to the US Preventive Services Task Force document. J Am Soc Hypertens. 2015;9:911-5.

3. Parati G, Ochoa JE, Bilo G, Agarwal R, Covic A, Dekker FW, Fliser D, Heine $\mathrm{GH}$, Jager KJ, Gargani L, et al. Hypertension in chronic kidney disease part 2. Hypertension. 2016;67:1102-10.

4. Drawz PE, Alper AB, Anderson AH, Brecklin CS, Charleston J, Chen J, Deo R, Fischer MJ, He J, Hsu C-Y, et al. Masked hypertension and elevated nighttime blood pressure in CKD: prevalence and association with target organ damage. Clin J Am Soc Nephrol. 2016;11:642-52.

5. Tang H, Gong W-Y, Zhang Q-Z, Zhang J, Ye Z-C, Peng H, Wang C, Lou T. Prevalence, determinants, and clinical significance of masked hypertension and white-coat hypertension in patients with chronic kidney disease. Nephrology. 2016;21:841-50.

6. Scheppach JB, Raff U, Toncar S, Ritter C, Klink T, Stork S, Wanner C, Schlieper G, Saritas T, Reinartz SD, et al. Blood pressure pattern and target organ damage in patients with chronic kidney disease. Hypertension. 2018;72:929-36.

7. Kushiro T, Kario K, Saito I, Teramukai S, Sato Y, Okuda Y, Shimada K. Increased cardiovascular risk of treated white coat and masked hypertension in patients with diabetes and chronic kidney disease: the HONEST Study. Hypertens Res. 2017;40:87-95.

8. Minutolo R, Gabbai FB, Agarwal R, Chiodini P, Borrelli S, Bellizzi V, Nappi F, Stanzione G, Conte G, De Nicola L. Assessment of achieved clinic and ambulatory blood pressure recordings and outcomes during treatment in hypertensive patients with CKD: a multicenter prospective cohort study. Am J Kidney Dis. 2014;64:744-52.

9. Wang C, Zhang J, Li Y, Ma X, Ye Z, Peng H, Lou T. Masked hypertension, rather than white-coat hypertension, has a prognostic role in patients with non-dialysis chronic kidney disease. Int J Cardiol. 2017;230:33-9.

10. Gao BXZL, Wang HY, Zhao MH. Chinese cohort study og chronic kidney disease: design and mrthods. Chin Med J. 2014;127:2180-5.

11. Yuan Q, Wang J, Peng Z, Zhou Q, Xiao X, Xie Y, Wang W, Huang L, Tang W, Sun $D$, et al. Neutrophil-to-lymphocyte ratio and incident end-stage renal disease in Chinese patients with chronic kidney disease: results from the Chinese Cohort Study of Chronic Kidney Disease (C-STRIDE). J Transl Med. 2019;2019:17.

12. Lv L, Wang J, Gao B, Wu L, Wang F, Cui Z, He K, Zhang L, Chen M, Zhao $\mathrm{MH}$. Serum uromodulin and progression of kidney disease in patients with chronic kidney disease. J Transl Med. 2018;16:316.

13. Brien E, Asmar R, Beilin L, Imai Y, Mallion JM, Mancia G, Mengden T, Myers M, Padfield P, Palatini P, Parati G. European Society of Hypertension recommendations for conventional, ambulatory and home blood pressure measurement. J Hypertens. 2003;21(5):821-48.

14. Brien E, Stergiou G, Asmar R, Beilin L, Bilo G, Clement D, Sierra A, Leeuw P, Dolan E, Fagard R, Graves J, Head GA, Imai Y, Kario K, Lurbe E, Mallion JM, Mancia G, Mengden T, Myers M, Ogedegbe G, Ohkubo T, Omboni S, Palatini P, Redon J, Ruilope LM, Shennan A, Staessen JA, Montfrans G, Verdecchia P, Waeber B, Wang J, Zanchetti A, Zhang Y. European Society of Hypertension Working Group on Blood Pressure Monitoring.: European Society of Hypertension position paper on ambulatory blood pressure monitoring. J Hypertens. 2013;31:1731-68.

15. Parati G SG, O'Brien E, Asmar R, Beilin L, Bilo G, Clement D, de la Sierra A, de Leeuw P, Dolan E, Fagard R, Graves J, Head GA, Imai Y, Kario K, Lurbe E, Mallion JM, Mancia G, Mengden T, Myers M, Ogedegbe G, Ohkubo T, Omboni S, Palatini P, Redon J, Ruilope LM, Shennan A, Staessen JA, vanMontfrans G, Verdecchia P, Waeber B, Wang J, Zanchetti A, Zhang Y; European Society of Hypertension Working Group on Blood Pressure Monitoring and Cardiovascular Variability:: European Society of Hypertension practice guidelines for ambulatory blood pressure monitoring. J Hypertens. 2014;32:1359-66.

16. Williams B, Mancia G, Spiering W, Agabiti Rosei E, Azizi M, Burnier M, Clement DL, Coca A, de Simone G, Dominiczak A, et al. 2018 ESC/ESH Guidelines for the management of arterial hypertension. Eur Heart J. 2018;39:3021-104.

17. Whelton PK, Carey RM, Aronow WS, Casey DE, Collins KJ, Dennison Himmelfarb C, DePalma SM, Gidding S, Jamerson KA, Jones DW, et al. 2017 ACC/AHA/AAPA/ABC/ACPM/AGS/APhA/ASH/ASPC/NMA/PCNA guideline for the prevention, detection, evaluation, and management of high blood pressure in adults: executive summary: a report of the American College of Cardiology/American Heart Association Task Force on Clinical Practice Guidelines. Hypertension. 2018;71:1269-324.

18. Stevens LA, Claybon MA, Schmid CH, Chen J, Horio M, Imai E, Nelson RG, Van Deventer M, Wang HY, Zuo L, et al. Evaluation of the chronic kidney disease epidemiology collaboration equation for estimating the glomerular filtration rate in multiple ethnicities. Kidney Int. 2011;79:555-62.

19. Andrassy KM. Comments on 'KDIGO 2012 clinical practice guideline for the evaluation and management of chronic kidney disease.' Kidney Int. 2013;84:622-3.

20. Pogue V, Rahman M, Lipkowitz M, Toto R, Miller E, Faulkner M, Rostand S, Hiremath L, Sika M, Kendrick C, et al. Disparate estimates of hypertension control from ambulatory and clinic blood pressure measurements in hypertensive kidney disease. Hypertension. 2009;53:20-7.

21. Minutolo R, Borrelli S, Scigliano R, Bellizzi V, Chiodini P, Cianciaruso B, Nappi F, Zamboli P, Conte G, De Nicola L. Prevalence and clinical correlates of white coat hypertension in chronic kidney disease. Nephrol Dial Transplant. 2007;22:2217-23.

22. limuro S, Imai E, Watanabe T, Nitta K, Akizawa T, Matsuo S, Makino H, Ohashi Y, Hishida A. Chronic kidney disease Japan cohort study G: clinical correlates of ambulatory BP monitoring among patients with CKD. Clin J Am Soc Nephrol. 2013;8:721-30.

23. Cohen JB, Lotito MJ, Trivedi UK, Denker MG, Cohen DL, Townsend RR. Cardiovascular events and mortality in white coat hypertension: a systematic review and meta-analysis. Ann Intern Med. 2019;170:853-62.

24. Pierdomenico SD, Cuccurullo F. Prognostic value of white-coat and masked hypertension diagnosed by ambulatory monitoring in initially 
untreated subjects: an updated meta analysis. Am J Hypertens. 2011;24:52-8

25. Cha R-h, Kim S, Ae Yoon S, Ryu D-R, Eun Oh J, Han S-Y, Young Lee E, Ki Kim D, Kim YS. Association between blood pressure and target organ damage in patients with chronic kidney disease and hypertension: results of the APrODiTe study. Hypertens Res. 2013;37:172-8.

26. Myers MG. Statistical analysis as a cause of white-coat hypertension. J Hypertens. 2017;35:707-9.

27. Drawz PE, Brown R, De Nicola L, Fujii N, Gabbai FB, Gassman J, He J, limuro S, Lash J, Minutolo R, et al. Variations in 24-h BP profiles in cohorts of patients with kidney disease around the world. Clin J Am Soc Nephrol. 2018;13:1348-57.

28. Wang F, He K, Wang JW, Zhao MH, Li Y, Zhang LX, Saran R, BraggGresham JL. Prevalence and risk factors for CKD: a comparison between the adult populations in China and the United States. Kidney Int Rep. 2018;3:1135-43.

29. Mancia G, Facchetti R, Cuspidi C, Bombelli M, Corrao G, Grassi G. Limited reproducibility of $\mathrm{MUCH}$ and $\mathrm{WUCH}$ : evidence from the ELSA study. Eur Hearty J. 2020;41:1565-71.

30. Cha RH, Lee H, Lee JP, Kang E, Song YR, Kim YS, Kim SG. Changes of blood pressure patterns and target organ damage in patients with chronic kidney disease: results of the APrODiTe-2 study. J Hypertens. 2017;35(3):593-601.

\section{Publisher's Note}

Springer Nature remains neutral with regard to jurisdictional claims in published maps and institutional affiliations.
Ready to submit your research? Choose BMC and benefit from:

- fast, convenient online submission

- thorough peer review by experienced researchers in your field

- rapid publication on acceptance

- support for research data, including large and complex data types

- gold Open Access which fosters wider collaboration and increased citations

- maximum visibility for your research: over $100 \mathrm{M}$ website views per year

At BMC, research is always in progress.

Learn more biomedcentral.com/submissions 